\title{
Proteinase-Activated Receptors in the Nucleus of the Solitary Tract: Evidence for Glial-Neural Interactions in Autonomic Control of the Stomach
}

\author{
Gerlinda E. Hermann, ${ }^{1}$ Montina J. Van Meter, ${ }^{1}$ Jennifer C. Rood, ${ }^{2}$ and Richard C. Rogers ${ }^{1}$ \\ ${ }^{1}$ Autonomic Neuroscience Laboratory and ${ }^{2}$ Clinical Chemistry Core, Pennington Biomedical Research Center, Louisiana State University System, Baton \\ Rouge, Louisiana 70808
}

\begin{abstract}
Bleeding head injury is associated with gastric stasis, a symptom of collapse of autonomic control of the gut described by Cushing around 1932. Recent work suggests that the proteinase thrombin, produced secondary to bleeding, may be the root cause. Results from our in vivo physiological studies show that fourth ventricular injection of PAR1 agonists, as well as thrombin itself, produced significant reductions in gastric transit in the awake rat. We expected that the PAR1 effect to inhibit gastric transit was the result of direct action on vagovagal reflex circuitry in the dorsal medulla. Surprisingly, our immunohistochemical studies demonstrated that PAR1 receptors are localized exclusively to the astrocytes and not the neurons in the nucleus of the solitary tract (NST; principal locus integrating visceral afferent input and part of the gastric vagovagal reflex control circuitry). Our in vitro calcium imaging studies of hindbrain slices revealed that PAR1 activation initially causes a dramatic increase in astrocytic calcium, followed seconds later by an increase in calcium signal in NST neurons. The neuronal effect, but not the astrocytic effect, of PAR1 activation was eliminated by glutamate receptor antagonism. TTX did not eliminate the effects of PAR1 activation on either glia or neurons. Thus, we propose that glia are the primary CNS sensors for PAR agonists and that the response of these glial cells drives the activity of adjacent (e.g., NST) neurons. These results show, for the first time, that changes in autonomic control can be directly signaled by glial detection of local chemical stimuli.
\end{abstract}

\section{Introduction}

Gastrointestinal (GI) stasis, gastric hypersecretion, gastric dilation, anorexia, nausea, and emesis are observed routinely in patients that have suffered bleeding head injuries (Young et al., 1992; Lu et al., 1997). This severe visceral malaise is also observed following traumatic bodily injury, burns, and surgical procedures that are associated with extensive bleeding, such as lung, heart, and liver transplantation (Berkowitz et al., 1995; Sodhi et al., 2002). There is a high degree of gastric feeding intolerance demonstrated by these patients; thus, they require aggressive total parenteral nutrition and, occasionally, invasive GI surgical intervention (Akindipe et al., 2000) for the maintenance of a positive energy and nitrogen balance. Additionally, there is a significant risk of aspiration that accompanies severe and prolonged gastric stasis such that intensive management of the airway is also required (Berkowitz et al., 1995). Clearly, failure to regulate gastric function is a significant cause of posttrauma morbidity and mortality.

The association of gastric stasis with severe trauma, surgery, and burn injury has been axiomatic in the clinical literature for $>70$ years [e.g., "Cushing's ulcer" (Young et al., 1992; Lu et al., 1997)]. Head trauma is associated with elevated intracranial pres-

Received Dec. 19, 2008; revised May 18, 2009; accepted June 17, 2009.

This work was supported by National Institutes of Health Grants HD47643, DK56373, and NS60664.

This article is freely available online through the J Neurosci Open Choice option.

Correspondence should be addressed to Dr. Gerlinda Hermann, Laboratory of Autonomic Neuroscience, Penning-

ton Biomedical Research Center, 6400 Perkins Road, Baton Rouge, LA 70808. E-mail: gerlinda.hermann@pbrc.edu. D0I:10.1523/JNEUROSCI.6063-08.2009

Copyright $\odot 2009$ Society for Neuroscience $\quad$ 0270-6474/09/299292-09\$15.00/0 sure (ICP) as well as the above-mentioned gastric complications. However, clinical studies that have attempted to correlate ICP with the degree of gastric dysfunction have not been successful (Larson et al., 1984). Experimental studies of ICP effects on gastric function are also inconsistent, unless extremely high pressures are used. That is, although application of $80 \mathrm{mmHg}$ intracerebroventricular pressure in rodents will produce a mild gastric stasis, this degree of intracranial pressure is four times greater than that observed in humans with "high" ICP after head trauma (Larson et al., 1984; Garrick et al., 1988). Furthermore, it is clear that high ICPs cannot be the factor responsible for the gastric dysfunction that is associated with systemic bleeding, burns, or trauma that occur outside the CNS. However, all of these injuries, including traumatic burn injury, are significant generators of thrombin (Lavrentieva et al., 2008).

An unusual class of receptor called protease-activated receptor (PAR) has been localized in rather high density to the medullary hindbrain (Weinstein et al., 1995), specifically in the dorsal vagal complex (DVC), an area responsible for vagal control of the stomach (Rogers et al., 2005). PARs represent a unique subclass of Gq-coupled receptors (Macfarlane et al., 2001) that are activated by proteinase cleavage of the extracellular $\mathrm{N}$ terminus of the receptor by serine proteases (e.g., thrombin). This "tethered ligand," a specific amino acid sequence on the tether (e.g., hexapeptide sequence SFLLRN-NH2), acts as the receptor agonist. The protease thrombin (produced as a consequence of bleeding, burns, or trauma) could act directly upon PAR receptors within the medullary hindbrain. 
Therefore, we propose that this interaction of thrombin (or its untethered ligand SFLLRN-NH2) with PAR1 receptors in the DVC causes the disruption of vagal control of the stomach, manifested as gastric stasis, nausea, emesis, and anorexia, that has been associated with bleeding, burns, or trauma. We will examine the potential mechanism by which thrombin or a specific PAR1 agonist modulates autonomic control of digestion by monitoring gastric emptying, examining the distribution of PAR1 in the DVC, and observing changes in calcium signaling in DVC cells in response to PAR1 receptor activation.

\section{Materials and Methods}

A total of 41 Long-Evans rats (200-400 g; either sex), obtained from the breeding colony located at Pennington Biomedical Research Center, were used in these studies. All animals were maintained in a room with a 12:12 h light-dark cycle with constant temperature and humidity, and given food and water ad libitum. All experimental protocols were performed according to the guidelines set forth by the National Institutes of Health and were approved by the Institutional Animal Care and Use Committees at the Pennington Biomedical Research Center.

\section{Fourth ventricle effects of thrombin and PAR1 agonist on gastric transit in awake rats}

Surgery. Rats ( $n=15$ ) were anesthetized with pentobarbital ( $50 \mathrm{mg} / \mathrm{kg}$, i.p.; Nembutal, Abbott Labs) and placed in a stereotaxic frame in the skull-level position. Using aseptic methods, the skull was exposed via midline incision and a $1 \mathrm{~mm}$ hole made on the midline of the temporal plate $11.3 \mathrm{~mm}$ caudal to bregma. Two additional holes were made in the skull $4 \mathrm{~mm}$ rostral to the first and $2 \mathrm{~mm}$ lateral to the midline; number 80 stainless screws were inserted into these holes as a support for the guide cannula. A 5-mm-long, 25 ga stainless-steel guide cannula (Plastics One) was then inserted and cemented to the skull and the support screws with dental acrylic. An obturator (5 mm length) was used to close the cannula until the injection of experimental agents immediately before the in vivo physiological studies. The scalp incision was sutured closed and animals were allowed to recover from this surgery for 5-7 d before physiological studies were begun.

C13-octanoate gastric transit. Gastric emptying rate in an awake, freely moving animal can be monitored by determining the rate of appearance of ${ }^{13} \mathrm{C}$ in respired $\mathrm{CO}_{2}$ that had been ingested as ${ }^{13} \mathrm{C}$-tagged sodium octanoate (Ghoos et al., 1993, 2002; Schoonjans et al., 2002). The appearance of ${ }^{13} \mathrm{C}$ in respired $\mathrm{CO}_{2}$ is indicative of the transit of the carbohydrate meal from the stomach to, and absorption by, the duodenum. One of the significant advantages of this method is that animals may be used multiple times in a repeated-measures design with intervening saline injections serving as controls. Thus, each animal can serve as its own control. Previous methods that used methyl red/cellulose meals were highly invasive as they required gavage and transit was determined by direct observation (ex vivo) of the remaining colored contents of the stomach. Thus, only one time data point per animal was possible. Further, this ${ }^{13} \mathrm{C}$ method captures the entire time course of the transit event (samples taken at 15 min intervals). Useful parameters include $T_{\text {lag }}$ (which corresponds with the time at which rate of excretion of ${ }^{13} \mathrm{CO}_{2}$ is maximum) and $T_{1 / 2}$ (gastric half-emptying time; i.e., time when half of the label that is to be excreted has been excreted) and the gastric emptying coefficient (GEC; a global index of rate of emptying). All three parameters can be derived through nonlinear regression methods [for mathematical curve fitting formulas and derivations, refer to Ghoos et al. (1993)]. However, $T_{\text {lag }}$ may also be identified simply as the time that corresponds to the peak amount of ${ }^{13} \mathrm{CO}_{2}$ produced per hour from the raw data plot, and $T_{1 / 2}$ is the time interval at which half of the total cumulative fractions of the administered dose has been excreted (i.e., half of the total area under the curve).

Animals permanently fitted with fourth ventricular guide cannulae [as described above and by Grill et al. (2002)] were adapted to handling and to spending several hours in the metabolic chamber before the beginning of the experimental sequence. Rats were food deprived overnight. In the morning, they were placed in the Plexiglas chambers; stable levels of $\mathrm{CO}_{2}$ (between 0.2 and $1.0 \%$ ) were established. The animals were presented with a $1 \mathrm{~g}$ test meal of waffle that had been labeled with $10 \mathrm{mg}$ of ${ }^{13} \mathrm{C}$ -
Table 1. Reagents for immunohistochemical identification

\begin{tabular}{lll}
\hline & Source; cat. no. & Dilution \\
\hline $\begin{array}{ll}\text { Primary antibodies } \\
\text { PAR1 }\end{array}$ & Santa Cruz; SC-8204; goat-polyclonal & $1: 50$ \\
NeuN & Chemicon; MAB377; mouse-monoclonal & $1: 500$ \\
GFAP & Dako; Z0334; rabbit-polyclonal & $1: 500$ \\
$\begin{array}{l}\text { Secondary antibodies } \\
\text { Biotin-SP }\end{array}$ & Jackson ImmunoResearch Laboratories; donkey & $1: 150$ \\
& anti-goat \\
Rhodamine-RedX & Jackson ImmunoResearch Laboratories; donkey & $1: 200$ \\
& anti-mouse or donkey anti-rabbit \\
Tyramide signal & & \\
amplification & & \\
TSA-FITC & PerkinElmer-NEN TSA kit & $1: 50$ \\
\hline
\end{tabular}

tagged sodium octanoate. Immediately upon consuming the doped waffle, rats received a fourth ventricular microinjection $(2 \mu \mathrm{l})$ of saline or agonist. Fourth ventricular injections were made by replacing the obturator with a 9-mm-long, 31 ga injection cannula through the guide cannula. The injection cannula was connected by PE10 tubing to a Hamilton syringe that contained either vehicle control (sterile saline) or test solutions (i.e., $4 \mathrm{U}$ thrombin; 1 or $10 \mathrm{nmol}$ of SFLLRN-NH2 dissolved in sterile saline).

For the sake of comparison to illustrate the effect of vagally mediated, motility-inhibiting anorectics (Flanagan et al., 1992) on this transit model, separate groups of animals were subjected to intraperitoneal injections of cholecystokinin (CCK; $5 \mu \mathrm{g} / \mathrm{kg}$ ) or lithium chloride ( $\mathrm{LiCl} ; 40 \mathrm{mg} / \mathrm{kg}$; isotonic for i.p. injection; volume $=0.6 \mathrm{ml} / 100 \mathrm{~g}$ of body weight) and compared with the transit patterns after intraperitoneal saline injections.

Appearance of ${ }^{13} \mathrm{C}$ in respired $\mathrm{CO}_{2}$ was monitored via $10 \mathrm{cc}$ air samples of the chambers taken at 15 min intervals over the subsequent $4 \mathrm{~h}$ and analyzed via stable isotope mass spectrometry (Finnigan Delta XP Isotope Ratio Mass Spectrometer; Thermo Scientific), similar to the method described by Schoonjans et al. (2002). GEC, $T_{\text {lag }}$, and $T_{1 / 2}$ are extracted by nonlinear regression from the raw data plots of percentage ${ }^{13} \mathrm{CO}_{2}$ in the expired gas as described by Ghoos et al. (1993).

Statistical analysis of ${ }^{13} \mathrm{C}$ transit data. Gastric transit parameters (GEC, $T_{\text {lag }}$, and $T_{1 / 2}$ ) were derived for each animal under each experimental condition. Each appropriate saline control (either i.p. or $4 \mathrm{~V}$ ) preceded the corresponding experimental condition by at least $2 \mathrm{~d}$ to allow for recovery from the overnight fast. Each animal served as its own control and comparisons were made as paired $t$ tests for each parameter under the five conditions; differences were considered statistically significant when $p<0.05$ (see Fig. 1).

\section{Distribution and phenotypic identification of DVC cells possessing PAR1}

Double immunohistochemical (IHC) staining techniques were used to locate and phenotypically identify PAR1 receptor-bearing elements in the CNS. Identification of these PAR1-positive components was investigated by IHC staining for neurons [i.e., neuron-specific nuclear antibody (NeuN) (Wolf et al., 1996)] versus glia [i.e., glial fibrillary acidic protein (GFAP) (Debus et al., 1983; Hermann et al., 2001)] as described earlier for the chemokine receptor CXCR4 (Hermann et al., 2008).

Animals $(n=12)$ were deeply anesthetized with urethane (ethyl carbamate, Sigma; $1 \mathrm{~g} / \mathrm{kg}$, i.p.) and transcardially perfused with PBS followed by $4 \%$ paraformaldehyde in PBS. Brains were removed, cryoprotected overnight in a $30 \%$ sucrose solution, and cut into $40 \mu \mathrm{m}$ sections on a freezing microtome. The free-floating histological sections were placed in PBS before dual immunofluorescence staining. [Note that between each incubation step, the sections were triple rinsed in PBS (5 min per rinse).] The tissue sections were pretreated with $1 \%$ sodium borohydride to remove residual aldehyde fixative. The blocking step consisted of $10 \%$ normal donkey serum, $0.3 \%$ Triton X-100, and PBS for $2 \mathrm{~h}$. Sections were incubated (overnight at room temperature on a shaker table) in a mixture of dual primary antibodies (Table 1).

Tissue sections were placed in a mixture of secondary antibodies for $2 \mathrm{~h}$ incubation. Following incubation with biotin-SP-donkey anti-goat 
secondary antibody, the sections were placed in Vector Elite avidinbiotin-peroxidase complex (Vector Laboratories) for $1 \mathrm{~h}$. Tissue sections were subjected to tyramide signal amplification to enhance the demonstration of the PAR1 receptor. The sections were mounted on Plus slides (Fisher) and coverslipped with ProLongGold (Invitrogen). Sections were viewed on a Nikon E800 fluorescence microscope and images collected with a Zeiss Axiocam (see Figs. 2-5).

\section{Live cell imaging}

Direct injection of Calcium Green dextran and SR101 into the solitary nucleus. Animals $(n=14)$ were anesthetized with urethane and placed in stereotaxic frame. Using aseptic technique, the occipital plate of the skull was removed to expose the medullary brainstem. A micropipette [ $30 \mu \mathrm{m}$ tip diameter; filled with $1 \%$ Calcium Green-1 AM (CAG; Invitrogen), $0.3 \%$ sulforhodamine 101 (SR101; Sigma Chemical), and 10\% pluronicDMSO (F-127, Invitrogen; in pH 7.2 Tris-PBS buffer)] was directed toward the medial solitary nucleus using a stereotaxic carrier. Four nanoinjections ( $40 \mathrm{nl}$ each) of the CAG-SR101 solution were made unilaterally into the NST at the level of calamus and $0.2,0.4$, and $0.6 \mathrm{~mm}$ anterior to calamus, all at a depth of $300 \mu \mathrm{m}$ below surface. (Note that the NST was specifically targeted as a result of the preliminary IHC data, which showed that both astrocytes and PAR1-ir are concentrated in the NST.) This injection pattern labeled the ipsilateral medial NST. CAG, a calcium reporter dye, labels both neurons and glia, while SR101 labels only astrocytes (Nimmerjahn et al., 2004) but does not interfere with CAG fluorescence. This method made it possible to easily discriminate astrocytes from neurons in a slice preparation. After $30 \mathrm{~min}$, the anesthetized rat was decapitated and the brainstem was quickly harvested. The caudal brainstem was glued to a ceramic block and placed in cold $\left(\sim 4^{\circ} \mathrm{C}\right)$ carbogenated $\left(95 \% \mathrm{O}_{2} ; 5 \% \mathrm{CO}_{2}\right)$ cutting solution (see recipe below). Coronal sections ( $300 \mu \mathrm{m}$ thick) were cut through the medulla using a Vibratome equipped with a sapphire knife. Slices were incubated in carbogenated normal Krebs at $29^{\circ} \mathrm{C}$ for at least $30 \mathrm{~min}$ before transfer to the imaging chamber.

Fluorescence imaging. Individual medullary slices were transferred to a temperature-regulated perfusion chamber (Bioptechs) and held in place with a harp-type pressure foot. Imaging was performed with a Nikon E600FN upright microscope equipped with a PerkinElmer CSU21 Ultraview spinning disk confocal illuminator and heated, water-immersion objectives. The recording chamber was continuously perfused at a rate of $2 \mathrm{ml} / \mathrm{min}$ with carbogenated Krebs warmed to $33^{\circ} \mathrm{C}$. Identification of SR101-labeled astrocytes was done using a $568 \mathrm{~nm}$ excitation, $607 \mathrm{~nm}$ emission filter set. CAG fluorescence and relative intracellular calcium levels were visualized when switching to the $488 \mathrm{~nm}$ excitation/509 nm emission filter. Solenoid valves were used to switch between the normal bathing solution and the experimental solutions (see recipes below).

In vitro drugs and solutions. The cutting solution contained the following (in mM): 110 choline chloride, $25 \mathrm{NaHCO}_{3}, 2.5 \mathrm{KCl}, 7 \mathrm{MgSO}_{4}-7 \mathrm{H}_{2} \mathrm{O}$, $1.25 \mathrm{NaH}_{2} \mathrm{PO}_{4}, 10$ glucose, and $0.5 \mathrm{CaCl}_{2}-2 \mathrm{H}_{2} \mathrm{O}$, bubbled with $95 \%$ $\mathrm{O}_{2} / 5 \% \mathrm{CO}_{2}$ during the entire cutting process. Normal Krebs contained the following (in mM): $124 \mathrm{NaCl}, 25 \mathrm{NaHCO}_{3}, 3.0 \mathrm{KCl}, 1 \mathrm{MgSO}_{4}-7 \mathrm{H}_{2} \mathrm{O}$, $1.5 \mathrm{NaH}_{2} \mathrm{PO}_{4}, 10$ glucose, and $1.5 \mathrm{CaCl}_{2}-2 \mathrm{H}_{2} \mathrm{O}$, bubbled with $95 \%$ $\mathrm{O}_{2} / 5 \% \mathrm{CO}_{2}$, continuously; osmolality was $300 \pm 10 \mathrm{mOsm} ; \mathrm{pH}=7.3$. As needed for the different experimental conditions, the following drugs were added to the Normal Krebs: glutamate (excitatory amino acid, 200 $\mu \mathrm{M}$; Sigma), SFLLRN-NH2 (PAR1-selective agonist, $20 \mu \mathrm{M}$; Peptides International), glutamate antagonist mixture [consisting of $1 \mathrm{~mm}$ kynurenate - an AMPA/kainate antagonist; $50 \mu \mathrm{M}$ MK-801 - an NMDA antagonist; and $300 \mu \mathrm{M} \mathrm{AP3}$ - a nonspecific metabotropic glutamate receptor antagonist (Paton et al., 1991; Virgili et al., 1995)], U73122 [10 $\mu \mathrm{M}$, phospholipase C antagonist-blocks the PAR1 phospholipase C transduction step (Hwang et al., 2005)], and tetrodotoxin [TTX; $1 \mu \mathrm{M}$; blocks voltage-gated sodium channels and action-potential-dependent transmitter release (Lee and Ruben, 2008)].

In vitro calcium signal analysis. Brainstem slices were challenged with $200 \mu \mathrm{M}$ glutamate for $30 \mathrm{~s}$, and relative intracellular calcium levels (i.e., $\left[\mathrm{Ca}^{2+}\right]_{\mathrm{i}}$ ) were monitored continuously from $10 \mathrm{~s}$ before glutamate exposure through $2 \mathrm{~min}$ after to visualize the viability and basal responsiveness of cells (both neural and glial) to glutamate. For the next $10 \mathrm{~min}$, the slices were exposed to normal Kreb's perfusion for washout; $\left[\mathrm{Ca}^{2+}\right]_{\mathrm{i}}$ was not monitored during this time. Next, the slices were exposed to SFLLRN-NH2 (20 $\mu \mathrm{M}$ in normal Kreb's for $60 \mathrm{~s})$; $\left[\mathrm{Ca}^{2+}\right]_{\mathrm{i}}$ of neurons and glia was monitored before and after SFLLRN-NH2 exposure. Alternatively, during the $10 \mathrm{~min}$ normal washout period, slices were exposed to either a glutamate antagonist mixture (kynurenate, MK-801, plus AP3) or to a phospholipase C antagonist (U73122) before the slices were exposed to SFLLRN-NH2. Relative changes in $\left[\mathrm{Ca}^{2+}\right]_{\mathrm{i}}$ in response to glutamate or SFLLRN-NH2 were quantified as changes in fluorescence: $(\Delta F / F) \%$, where $F$ is the fluorescence intensity within an area of interest (e.g., the outline of an SR101-labeled astrocyte or a non-SR101-labeled NST neuron) before stimulation and $\Delta F$ is the change from this value resulting from cellular activity (Helmchen, 2000). Background fluorescence (i.e., noninvolved areas in same field) was subtracted from both $\Delta F$ and $F$. The following parameters were extracted from the calcium signal data from each cell examined under normal versus blockade conditions: magnitude of response [peak $(\Delta F / F) \%$ ], time of onset of calcium response, and time to peak calcium response.

These parameters were determined for each region of interest (ROI; individual glia or neuronal cells) and could be compared statistically. Specifically, magnitudes of responses to SFLLRN-NH2 by glia were compared with that elicited in neurons as unpaired $t$ tests. Data regarding response time of onset or time to peak were also compared as unpaired $t$ tests. Modulation of response magnitudes to SFLLRN-NH2 by either glia or neurons as a consequence of glutamate antagonists, PLC inhibitors, or neuronal transmission blocker (TTX) were compared in one-way ANOVAs across each cell type. $p$ values $<0.05$ were considered significantly significant; Dunnett's posttest comparisons were performed (see Fig. 7).

\section{Results}

\section{Thrombin and SFLLRN-NH2 effects on gastric transit in the neurally intact, awake rat}

Microinjection of thrombin [4 $\mathrm{U}$; low end of the dose range (4-20 U) used to model stroke; note that $50 \mu$ l blood clot produces $\sim 15$ U of thrombin (Hua et al., 2007)] or the PAR1selective agonist SFLLRN-NH2 (1 or $10 \mathrm{nmol}$ ) into the fourth ventricle, overlying the DVC, caused a significant reduction in gastric transit as measured by $T_{\text {lag }}$ and $T_{1 / 2}$ (Fig. 1 ). The degree of transit suppression is similar to that produced by intraperitoneal injection of CCK-8 [ $5 \mu \mathrm{g} / \mathrm{kg}$; produces a significant suppression of gastric motility as well as feeding behavior (Flanagan et al., 1992)]. In addition, both thrombin and the higher dose of SFLLRN-NH2 $(10 \mathrm{nmol})$ also slowed the overall gastric emptying coefficient relative their respective saline controls.

The gastric transit effects of intracerebroventricular thrombin may be potentially confounded by psychomotor difficulties in that the rats tended to appear catatonic for $\sim 1 \mathrm{~h}$ after the intraventricular injection. [Intracranial injection of thrombin has been reported to produce seizure activity in rats (Lee et al., 1997; Kelly, 2008).] While microinjections of the hexapeptide ligand, SFLLRN-NH2, suppressed gastric transit parameters, it was not accompanied by seizure-like effects.

As a radical point of comparison, intraperitoneal injection of $\mathrm{LiCl}$ [commonly used to produce visceral aversion (Coil et al., 1978)] produced a profound suppression of transit that lasted longer than the duration of the experiment (Fig. $1 E$ ). Since there was no discernible transit in the $\mathrm{LiCl}$ case, the regression model failed to extract any estimates for the overall gastric emptying coefficient.

\section{Immunohistochemical identification of cell types possessing PAR1 receptors}

Our physiological observations of slowed gastric transit in response to intracerebroventricular administration of PAR agonists would suggest that this is a neurally mediated activity 
A
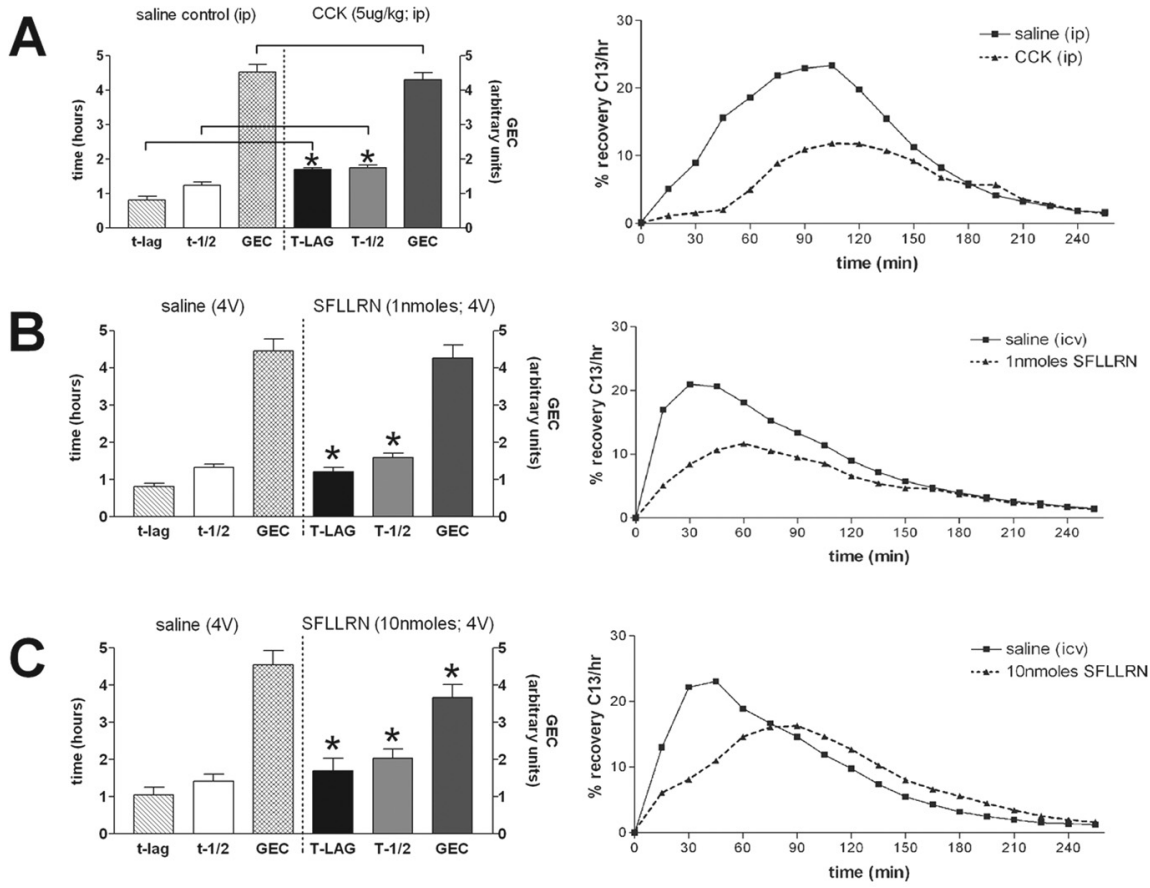

D
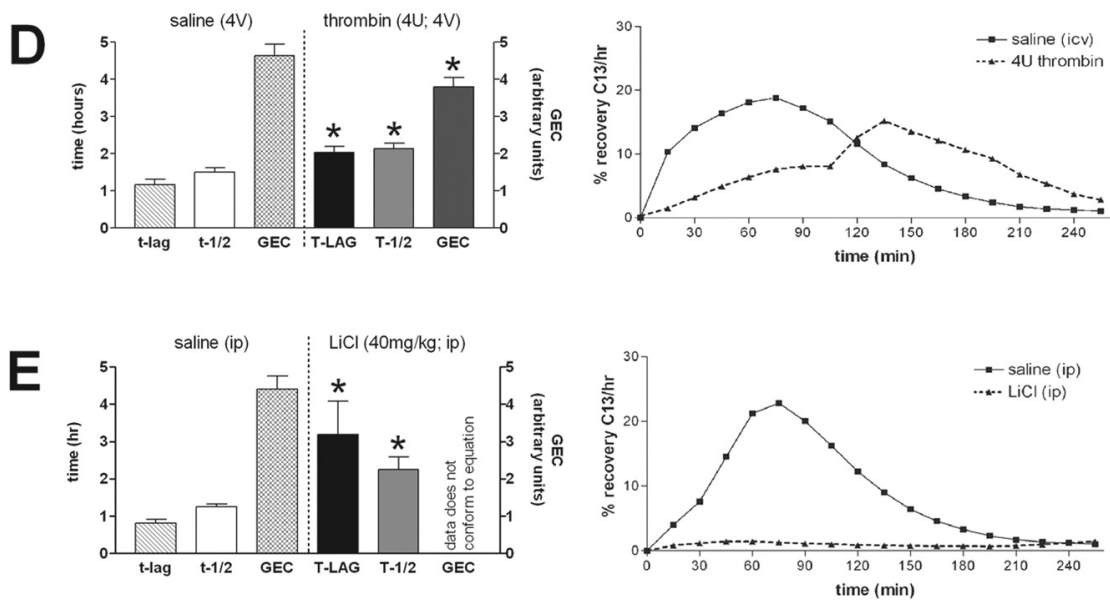

Figure 1. C13-octanoate gastric transit. Gastric emptying rate in an awake, freely moving animal can be monitored by determining the rate of appearance of ${ }^{13} \mathrm{C}$ in respired $\mathrm{CO}_{2}$ that had been ingested as ${ }^{13} \mathrm{C}$-tagged sodium octanoate-doped meal. ${ }^{13} \mathrm{C}$ in respired $\mathrm{CO}_{2}$ is indicative of the transit of the carbohydrate meal from the stomach to the duodenum. This ${ }^{13} \mathrm{C}$ method captures the entire time course of the transit event (samples taken at $15 \mathrm{~min}$ intervals) and is displayed in the right-hand graphs. Specific parameters of this transit can be extracted for comparisons: $T_{\text {lag }}$ corresponds with the time at which rate of excretion of ${ }^{13} \mathrm{CO}_{2}$ is maximal, $T_{1 / 2}$ is the gastric half-emptying time (time when half of the label that is to be excreted has been excreted) and the GEC (a global index of rate of emptying). Each animal served as its own control. That is, the first session the animal receives the control injection (saline either i.p. or 4V, as appropriate); the next session the animal receives the test injection. Therefore, paired $t$ test comparisons could be made between the saline control and the agonist condition for each animal. Examples of such paired gastric transit experiments of individual animals are seen in the right-hand graphs. In the left-hand column are group averages for the gastric transit parameters under each condition; statistical comparisons were only made within each condition group. Microinjection of thrombin (4 U) or the PAR1-selective agonist SFLLRN-NH2 (1 or $10 \mathrm{nmol}$ ) into the fourth ventricle caused a significant reduction in gastric transit as measured by $T_{\text {lag }}$ and $T_{1 / 2}(\boldsymbol{B}-\boldsymbol{D})$. Thrombin and $10 \mathrm{nmol}$ SFLLRN-NH2 also slowed the overall GEC compared with their respective saline controls $(\boldsymbol{C}, \boldsymbol{D})$. For the sake of comparison, the dynamics of gastric transit suppression caused by intraperitoneal injection of either CCK-8 or LiCl are shown in $\boldsymbol{A}$ and $\boldsymbol{E}$, respectively. ${ }^{*} p<0.05$.

ultimately due to the modulation of vagal efferent projections to the gut (Rogers et al., 2005). However, much to our surprise, our double IHC studies of the dorsal vagal complex showed that PAR1-positive staining overlaps that of GFAP-positive (astrocytes) cells and fibers (Figs. 2,3) in the NST. In contrast, there was no obvious overlap of PAR1-positive staining with cells immunopositive for NeuN (i.e., neurons). As Figure 2 illustrates, the medial NST (mNST) contains a dense concentration of astrocytes relative to the adjacent areas, including the dorsal motor nucleus of the vagus (DMN) and solitary tract (ST). Together these results suggest that PAR1 agonists act primarily on astrocytes in the NST, as opposed to vagal afferent fibers in the ST, NST neurons, or DMN neurons. With this in mind, we focused our live cell imaging efforts on the mNST.

\section{Live cell calcium imaging of the effects of PAR1 agonist action on hindbrain slices}

In the in vitro slice preparation, glia and neurons are clearly discriminable by basic morphology, uptake of SR101 label, and calcium influx response to $200 \mu \mathrm{M}$ glutamate (Figs. 4, 5). Even without SR101 counterstaining, astrocyte cell bodies appear smaller, more angular, and brighter in appearance, due to their higher resting levels of cytoplasmic calcium, than neurons (Kang and Nedergaard, 2000). Further, calcium responsiveness to $200 \mu \mathrm{M}$ glutamate discriminates NST neurons from glia (Fig. 4). NST neurons produce an immediate increase in intracellular calcium [average $(\Delta F / F) \%=46 \% \pm 5.5$ ] to the $30 \mathrm{~s}$ exposure to $200 \mu \mathrm{M}$ glutamate challenge, while NST astrocytes produce little or no increase in intracellular calcium [average $(\Delta F / F) \%=9 \% \pm 2.4$ ] to this brief pulse exposure to relatively lowconcentration glutamate. A mixture of glutamate antagonists (kynurenate, MK-801, and AP3 meant to block AMPA, NMDA, and metabotropic receptors, respectively) was required to eliminate the neuronal response to $200 \mu \mathrm{M}$ glutamate (data not shown).

The PAR1 agonist SFLLRN-NH2 produced a relatively rapid and dramatic increase in glial cytoplasmic calcium with an overlay of oscillation (Figs. 5, 6). This characteristic glial response was followed ( $\sim 5$ s later) by a delayed, monotonic increase in calcium signal in NST neurons (Fig. 5D, Table 2). Both the onset and time of peak response to SFLLRN-NH2 were significantly faster than those seen in the neurons (Table 2) (unpaired $t$ tests; $p<$ 0.001). These observations suggest that glia are the primary responders that, in turn, activate the neurons during exposure to SFLLRN-NH2.

The magnitude of response to SFLLRN-NH2 is nearly threefold greater in glia than neurons (Figs. 5, 6, Table 3). Pretreatment with the glutamate antagonist mixture essentially eliminated the apparent delayed effect of SFLLRN-NH2 on neurons; while the glial response was reduced only by approximately one-third (Fig. 6). In contrast, pretreatment with the phospho- 

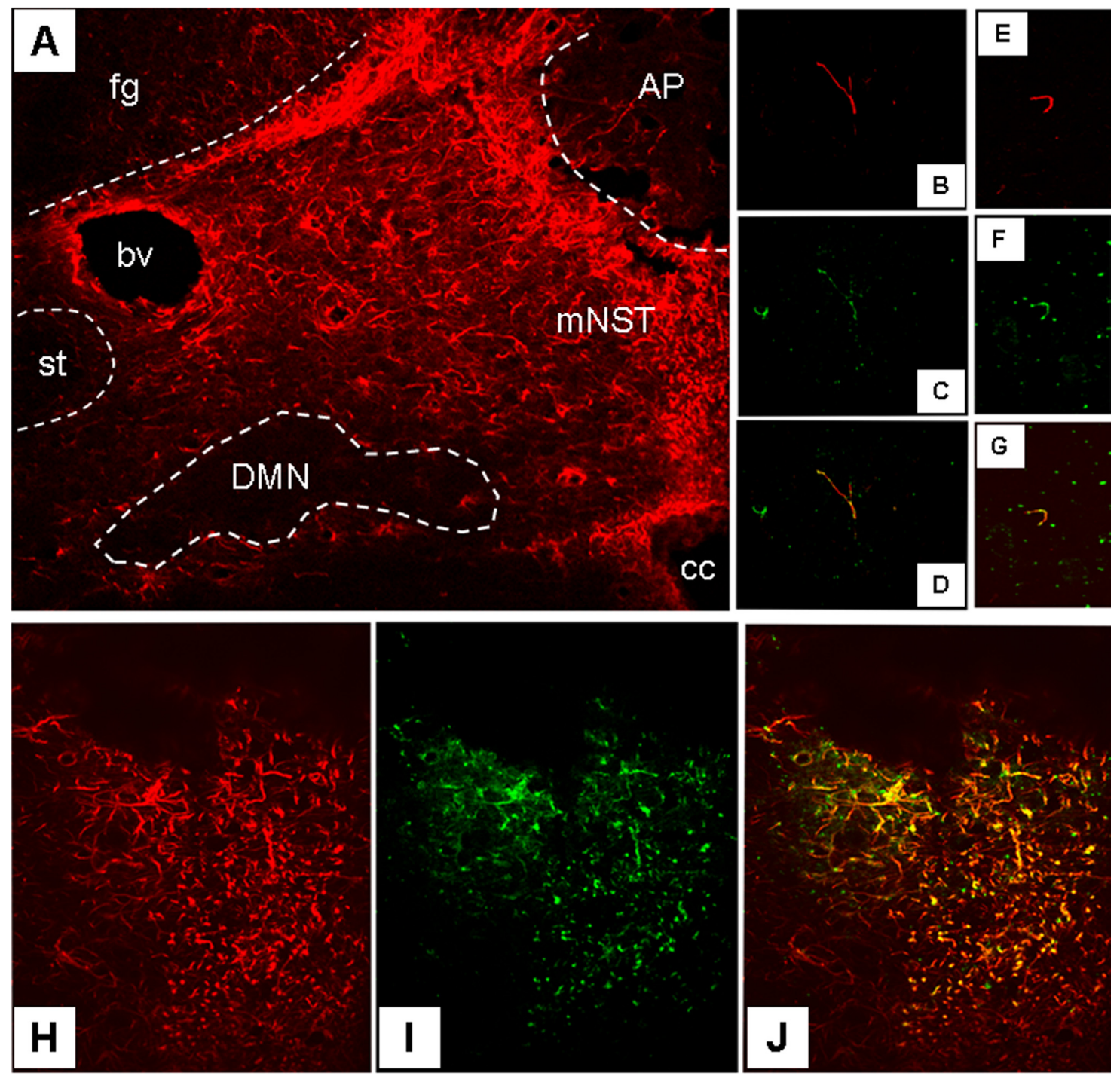

Figure 2. IHC identification of location of PAR1-positive cells in the DVC. A, Low-power view of the distribution of GFAP-ir astrocytes in the dorsal vagal complex. Note that the mNST contains substantially more astrocytes than surrounding areas, including the DMN and the ST. AP, Area postrema; bv, blood vessel; $\boldsymbol{C}$, central canal; fg, fasciculus gracilis. $\boldsymbol{B}$-D, Single astrocytic fiber (GFAP-ir, red) in DMN possesses PAR1 receptors (PAR1-ir, green) as seen in merged image (D). The DMN is practically devoid of astrocytic profiles, though the few that are there show colocalization with PAR1-ir. $E-G$, Single GFAP profile within the fascicles of the ST; also possesses PAR1 receptors as seen in the merged image (G). This area shows the same pattern as seen in the DMN. $\boldsymbol{H}-\boldsymbol{J}$, Dense astrocytic label (GFAP-ir) in the mNST is extensively double labeled for PAR1-ir. Scale bars: $\boldsymbol{A}, 200 \mu \mathrm{m} ; \boldsymbol{B}-\boldsymbol{D}, 20 \mu \mathrm{m} ; \boldsymbol{E}-\mathbf{G}, 15 \mu \mathrm{m} ; \boldsymbol{H}-\boldsymbol{J}, 30 \mu \mathrm{m}$.

lipase C (PLC) antagonist, U73122, blocked the SFLLRN-NH2 effect on both glia and neurons (Fig. 6, top panel, Table 3). Last, while perfusion of the slice with SFLLRN-NH2 in the presence of TTX (Fig. 6) caused a slight but statistically significant decrease (not unlike that seen with glutamate blockade) in the magnitude of the glial response, there was no change in the neuronal response. This would suggest that the glia are potentially under the tonic influence of neurons or vagal afferents.

Together these data suggest that not only are glia the primary targets of SFLLRN-NH2, but astrocytes probably use glutamate to subsequently activate the adjacent NST neurons. Given that the PAR1 transduction mechanism has been principally linked to PLC (Macfarlane et al., 2001; Hwang et al., 2005), our observation that PLC blockade eliminates the activation of both astrocytes and neurons in response to SFLLRN-NH2 reinforces our interpretation that glia are the primary targets of SFLLRN-NH2 activation, which would normally be passed to surrounding NST neurons via glutamate gliotransmission.

\section{Discussion}

Patients with traumatic brain injury or bleeding bodily trauma are chronically unable to maintain nutritional homeostasis (Akindipe et al., 2000). Historically, more interest has been directed to the cachectic, hypermetabolic state that accompanies such injuries. A less appreciated cause of morbidity is the chronic gastric stasis. In the case of closed head injury, an increase in intracranial pressure had been thought to be the main culprit. However, ventricular pressures recorded from head injury patients do not correlate with the occurrence of gastric stasis (Larson et al., 1984). The correlation between bleeding trauma and gastrointestinal autonomic dysfunction, while clear, has been difficult to explain. With these factors in mind, it seemed more likely that mechanisms associated with bleeding, rather than CNS pressure, could have a direct effect on the autonomic control of the gut. Thrombin, a protease generated as a consequence of the clotting cascade, can have devastating effects on neuronal excitability in the 

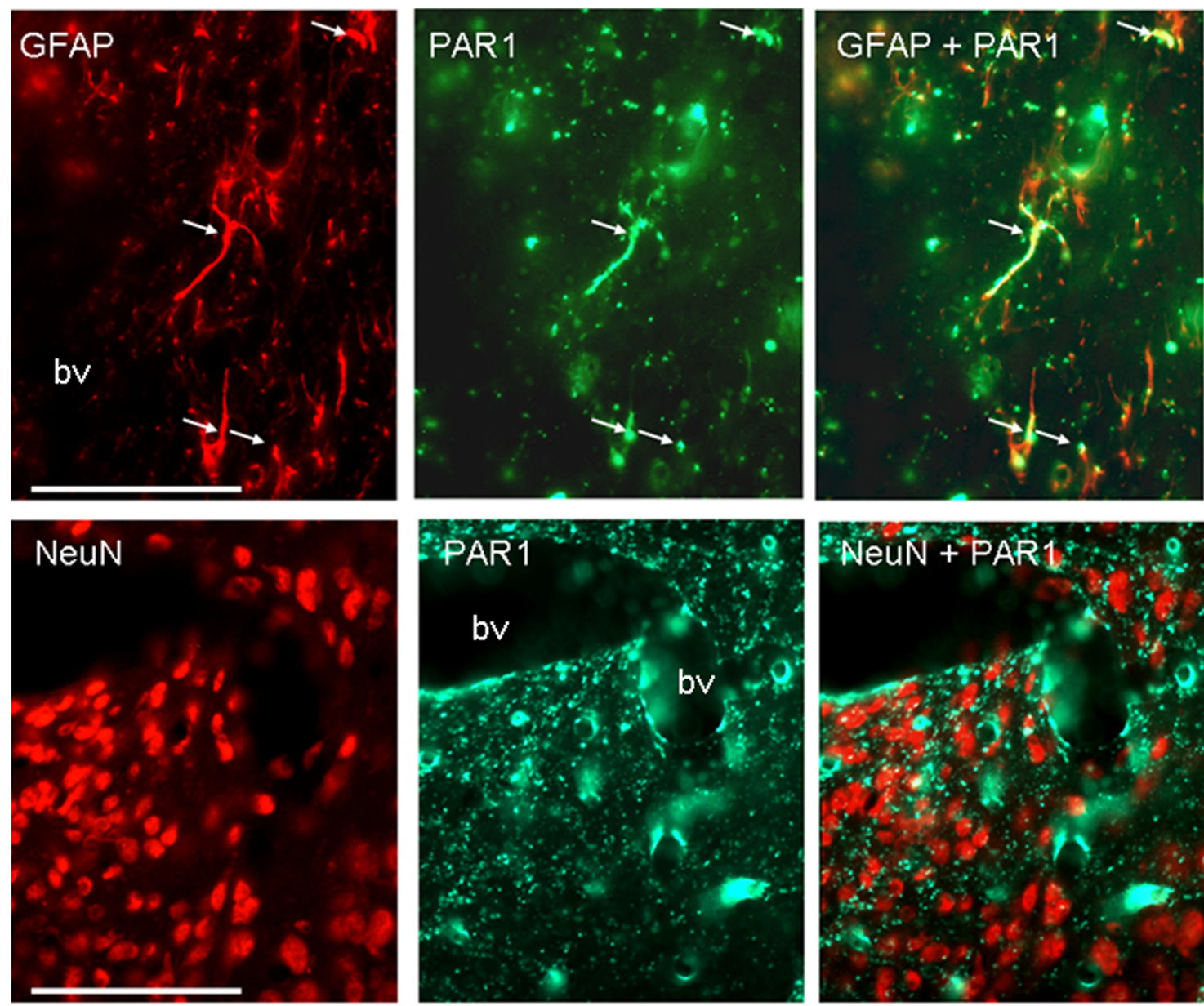

Figure 3. IHC identification of PAR1-positive cell types in NST. Double IHC studies demonstrated that PAR-ir (middle panels) is colocalized on astrocytes (GFAP-ir; top panels) but not on neurons (NeuN-ir; bottom panels) in the NST. Examples of colocalization are shown at arrows. bv, Blood vessels. Scale bars: top, $20 \mu \mathrm{m}$; bottom, $100 \mu \mathrm{m}$.
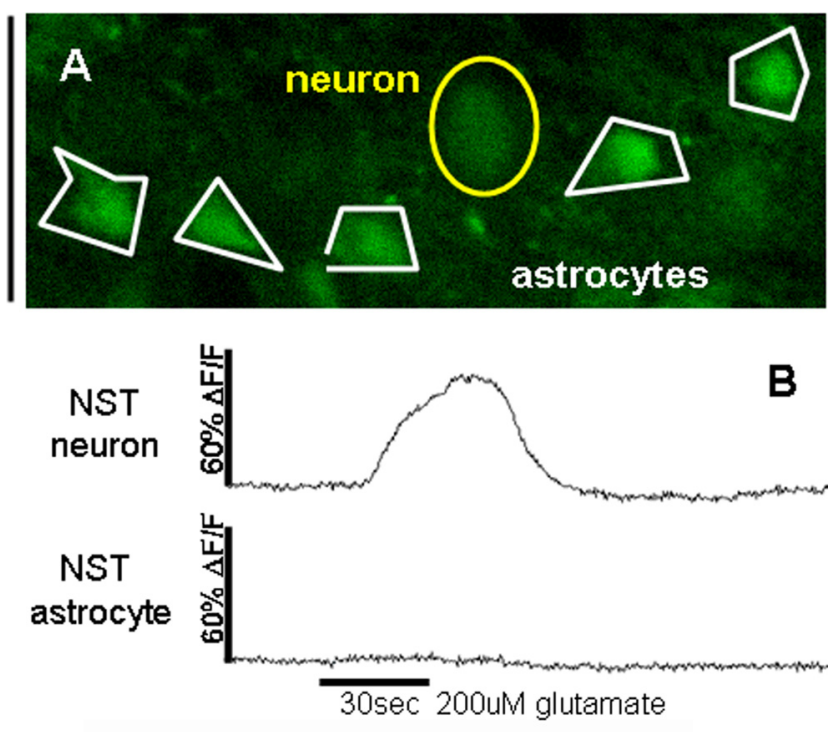

Figure 4. Live cell imaging identification of neuronal versus glial characteristics. $A$, Hindbrain astrocytes (outlined in white) tend to be smaller, more irregular in shape, and have higher resting calcium levels relative to neurons (outlined in yellow). $\boldsymbol{B}$, Response of individual neuron or astrocyte to 30 s exposure to $200 \mu \mathrm{m}$ glutamate. hippocampus and these PAR1-mediated effects are probably responsible for seizure activity that accompanies the appearance or delivery of the protease in the CNS (Kelly, 2008). The mechanism connecting thrombin with neuron hyperexcitability is not well understood. However, proteases are involved in long-term potentiation and activation of glutamatergic mechanisms has been associated with thrombin-induced seizures (Tomimatsu et al., 2002). In any event, the present study suggests that a thrombinmediated derangement of autonomic control operating through PAR1 receptors at the level of the hindbrain astrocyte is a good possibility and may be responsible for the collapse in autonomic control of digestion that occurs secondary to traumatic injury.

The dorsal medulla contains the neural circuitry essential to the vagal reflex regulation of the stomach (Rogers et al., 2005). NST neurons that receive visceral afferent inputs are also essential to the regulation of feeding behavior, especially satiation. Earlier work by Weinstein et al. (1995) demonstrated that mRNA for PAR1 receptors is densely localized to the NST and dorsal motor nucleus of the vagus, hindbrain structures containing critical gastric vagovagal reflex circuitry. However, this earlier work used a radiation-based in situ hybridization method that showed the general histological location of PAR1 receptor expression but not the phenotype of the cells involved.

We show that fourth ventricular application of SFLLRN-NH2 and thrombin causes a significant reduction in gastric transit. This implies that activation of PAR1 receptors, ultimately, activates solitary nucleus neurons involved in vagal reflex control of 

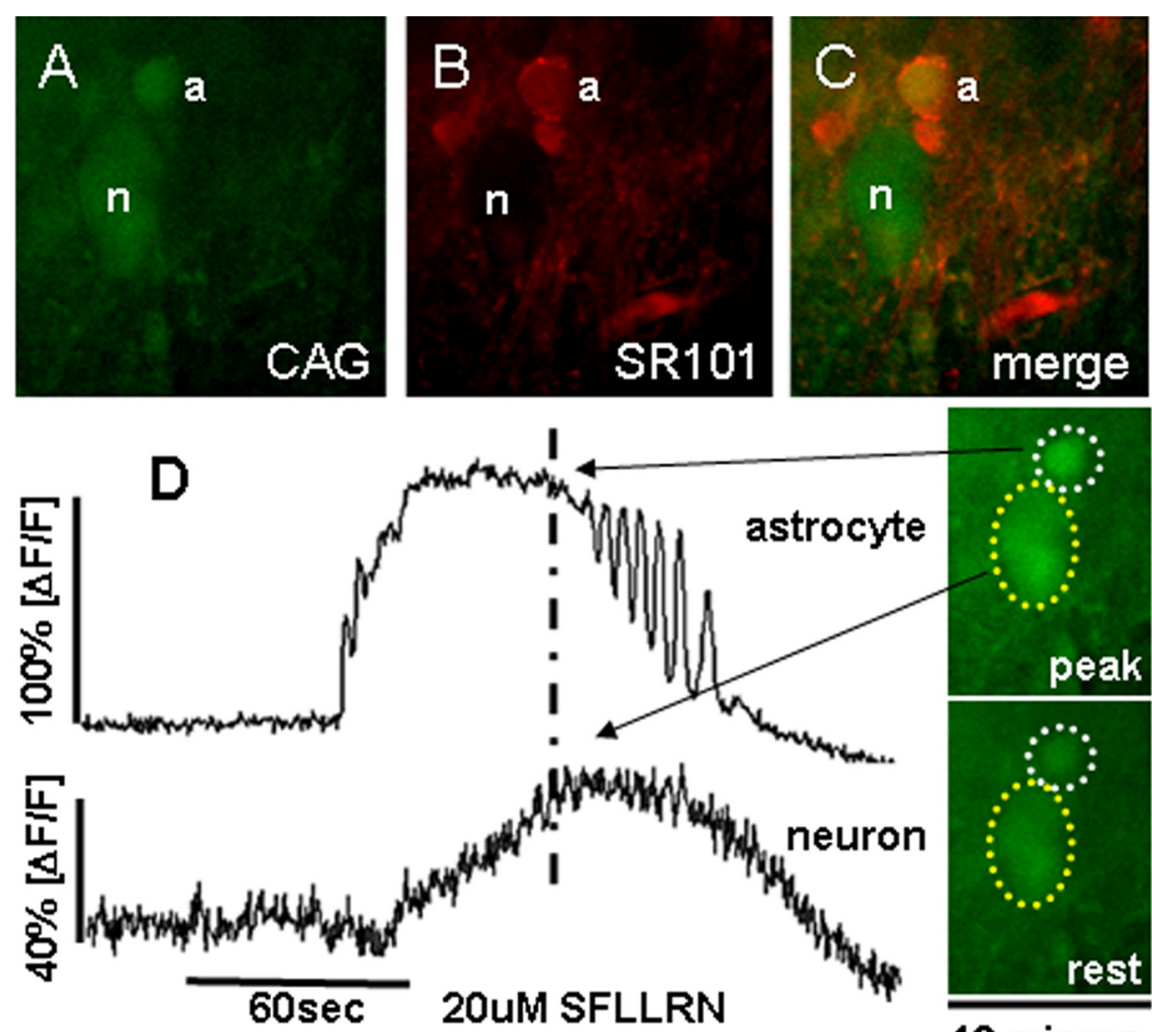

Figure 5. Response patterns of astrocytes and neurons to SFLLRN-NH2. $A$, CAG, the $\mathrm{Ca}^{2+}$ reporter dye, is taken up by both astrocytes (a) and neuronal cells (n). $\boldsymbol{B}$, SR101 astrocyte-specific vital dye staining. $\boldsymbol{C}$, Same field as both $\boldsymbol{A}$ and $\boldsymbol{B}$; demonstration of in vitro glial and neuronal identification. $A-C$ double fluorescence confocal images were taken through 509 and $607 \mathrm{~nm}$ bandpass filters. $\boldsymbol{D}$, Responses of the same identified glial and neuron cells in $\boldsymbol{A}-\mathbf{C}$ following $60 \mathrm{~s}$ bath exposure to $20 \mu \mathrm{m}$ SFLLRN-NH2. Note delay in onset and peak of neuronal response relative to glial response. Raw $500 \mathrm{~nm}$ long-pass filtered image frames on the right illustrate relative calcium levels in the astrocyte and neuron (outlined in dotted circles) at the approximately the peak of the SFLLRN-NH2 response (indicated by dashed vertical line through the response curves) and at rest.

Table 2. Timing parameters of response to $20 \mu \mathrm{M}$ SFLLRN-NH2

\begin{tabular}{llc}
\hline & Glia $(n=104)$ & Neurons $(n=51)$ \\
\hline Onset of response (s) & $65 \pm 1.0$ & $71 \pm 1.5^{*}$ \\
Time of peak response (s) & $84 \pm 1.8$ & $102 \pm 2.6^{*}$ \\
\hline
\end{tabular}

Values are average \pm SEM. ${ }^{*} p<0.001$, unpaired $t$ tests.

the gut. Given that activation of NST neurons has been shown to cause a strong, vagally mediated suppression of gastric tone, motility, and transit (Rogers et al., 2005), it had been our assumption that the relevant PAR1 receptors were localized to NST neurons. However, our immunohistochemical results suggested that these receptors are, in fact, localized to astrocytes and not neurons within this nucleus. This finding is supported by the calcium imaging study which showed that, as a population, astrocytes are activated by SFLLRN-NH2 seconds earlier than neurons in the area. Further, increases in NST neuronal calcium after exposure to SFLLRN-NH2 are essentially eliminated by a glutamate antagonist mixture, while NST glia still respond to SFLLRN-NH2 (though their response is muted relative to the response seen under normal conditions). This muted response to SFLLRN$\mathrm{NH} 2$ by glia after glutamate antagonist mixture suggests that glia in the NST may be tonically exposed to glutamate. One potential source of glutamate in the NST-slice preparation is spontaneous release from vagal afferent terminals (Lawrence, 1995). If correct, then it is possible that glial sensitivity to agonist stimulation could be modulated by activity in vagal afferents. Indeed, TTX had the
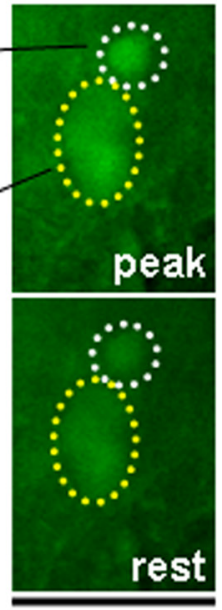

10 micron

same effect on the glial response to SFLLRN-NH2 as complete block of glutamate transmission (Fig. 6); an $\sim 30 \%$ reduction in responsiveness to the hexapeptide. TTX had no effect on the responses of neurons to SFLLRN-NH2. Together, these results show that SFLLRN-NH2 primarily activates astrocytes in the NST and these astrocytes, in turn, cause a glutamate-mediated increase in cytoplasmic calcium in NST neurons. Our observations strongly suggest that the glia are potentially under the tonic influence of afferent neuronal inputs. If this mechanism is correct, then vagal afferent stimulation should cause calcium waves in NST astrocytes as well as neurons. We have collected preliminary evidence that this is the case (Hermann and Rogers, 2009). Finally, both glial and neural responses to SFLLRN-NH2 are blocked by the PLC antagonist U73122. This would be expected given that the PAR1 transduction mechanism is principally linked to PLC (Macfarlane et al., 2001; Hwang et al., 2005). Clearly, if the glial response to SFLLRN$\mathrm{NH} 2$ is blocked by PLC antagonism, then the subsequent activation of neurons by glia is also lost.

The classic neurophysiological role for the astrocyte in the control of CNS function has been passive and supportive. In this view, the astrocyte controls the extracellular nutrient, metabolite, and ionic environment for the neuron, while also working to dispose of released neurotransmitters and their break-down products (Volterra and Meldolesi, 2005). While astrocytes certainly perform these important functions, recent neurophysiological studies in mixed neuralglial culture suggest that astrocytes are critical regulators of neuronal excitability and synaptic efficiency (Haydon and Carmignoto, 2006). Astrocytes possess a broad array of receptors for neurotransmitters, hormones, cytokines, and other agonist peptides. Agonist inputs to these astrocytic receptors can cause dramatic increases in cytoplasmic calcium (Haydon and Carmignoto, 2006), which, in turn, is coupled to astrocytic release of a variety of neuroactive substances, especially glutamate.

Agonist-induced calcium signals in astrocytes can cause the delayed activation of adjacent neurons (Parpura and Haydon, 2000). Neurophysiological studies in neuronal-glial cocultures suggest that the delayed signal generated in neurons may be the result of a calcium-induced exocytosis of glutamate from the glia (Parpura and Haydon, 2000). Depending on the circuitry under study, astrocytic glutamate release can affect neuronal excitability through action on metabotropic, NMDA, and/or AMPA receptors (Haydon and Carmignoto, 2006). Again, depending on the specifics of the circuitry, these astrocyte-glutamate-mediated effects can increase or decrease the postsynaptic sensitivity of neurons to presynaptic input (Fellin et al., 2006). While there is strong evidence for astrocytic glutamate release exerting dominating effects on neuronal function, recent studies show that similar effects can also be produced by astrocytic release of other agonists including serine, ATP, or nitric oxide (Haydon and Car- 

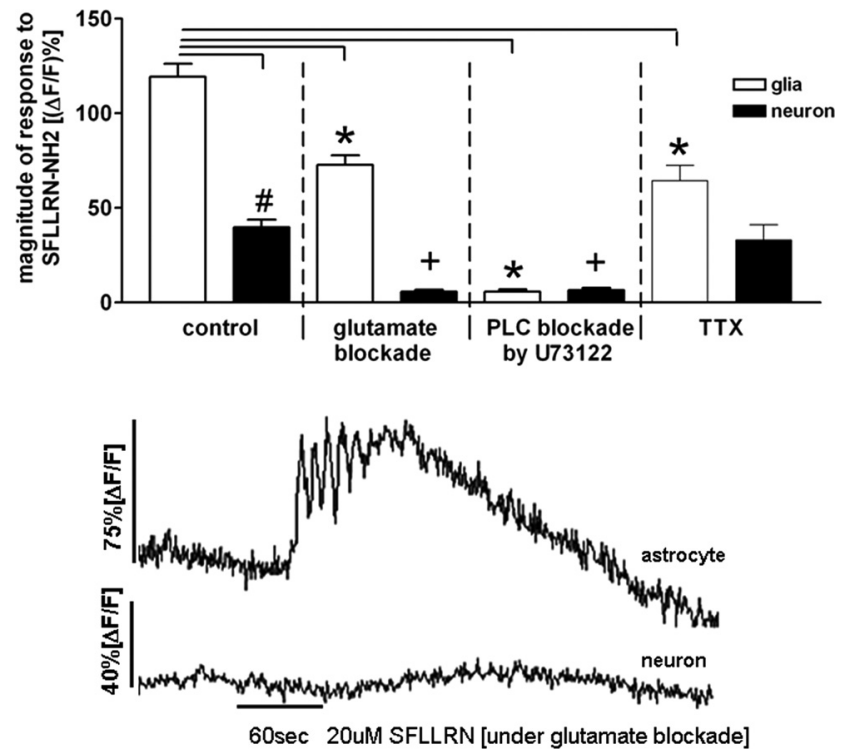

Figure 6. Response patterns of astrocytes and neurons to SFLLRN-NH2 during blockade. Glia and neurons have different response patterns (e.g., time of onset and magnitude) to SFLLRN$\mathrm{NH2}$. Magnitude of response to SFLLRN-NH2 is nearly three times greater in glia than neurons (left panel; " ${ }^{*}$ unpaired $t$ test, $p<0.001$ ).These differences are further delineated in the presence of a glutamate antagonist mixture (kynurenate, MK-801, plus AP3) which abolishes the neuronal "response" to SFLLRN-NH2, while the glial response appears only slightly muted (bar graph and raw data trace). When pretreated with the PLC inhibitor, U73122, for $10 \mathrm{~min}$ before the SFLLRN-NH2 challenge, PLC inhibition abolished the SFLLRN-NH2 response in both glia and, in turn, neurons. Last, when SFLLRN-NH2 is applied in the presence of TTX, the fundamental response to SFLLRN-NH2 in both glia and neurons is still seen. Unlike the glutamate blockade condition, under which the neuronal response was essentially abolished, under TTX conditions (which should be blocking action potential-dependent transmitter release), the neuronal response is not affected. These results provide evidence that the glia are the primary targets of SFLLRN-NH2, that neurons are subsequently activated by glutamate release from activated glia, and that glia may be under tonic vagal afferent influence. *ANOVA glial response, Dunnett's posttest $p<0.001 ;{ }^{+}$ANOVA neuronal response, Dunnett's posttest $p<0.001$.

Table 3. Magnitude of response to $20 \mu \mathrm{m}$ SFLLRN-NH2

\begin{tabular}{lllll}
\hline & Control & $\begin{array}{l}\text { Glutamate } \\
\text { blockade }\end{array}$ & PLC blockade & TTX \\
\hline Glia & & & & \\
$\quad$ Ave \pm SEM & $110 \pm 5.8$ & $73 \pm 5.1^{*}$ & $5.8 \pm 1.0^{*}$ & $64 \pm 8.1^{*}$ \\
$\quad n$ & 55 & 13 & 14 & 23 \\
$\begin{array}{l}\text { Neurons } \\
\quad \text { Ave } \pm \text { SEM }\end{array}$ & $40 \pm 3.2$ & $5.8 \pm 1.1^{+}$ & $6.5 \pm 1.3^{+}$ & $33 \pm 8.0$ \\
$n$ & 29 & 14 & 17 & 9 \\
\hline
\end{tabular}

Ave, Average. *ANOVA glial response $F_{(3,101)}=34, p<0.0001$; Dunnett's posttest $p<0.001 .{ }^{+}$ANOVA neuronal response $F_{(3,65)}=30, p<0.0001$; Dunnett's posttest $p<0.001$.

mignoto, 2006). These candidate "gliotransmitters" will certainly affect the excitability of the NST.

Astrocytes are also implicated in the presynaptic regulation of afferent neuronal signal traffic. Glial release of ATP can act at a variety of presynaptic purinergic receptors to produce a range of circuit-specific effects. In hippocampal culture models, glial release of ATP and its subsequent conversion to adenosine by an ectoenzyme, ultimately results in a presynaptic, A1 receptormediated inhibition of excitatory transmission (Newman, 2003). ATP release from glia might also be expected to have potent effects to increase neuronal cytoplasmic calcium and, ultimately, glutamate release from vagal afferent terminals that possess the ATP-gated P2X3 calcium channels (Jin et al., 2004; Shigetomi and Kato, 2004; Rogers et al., 2006a,b). Though intriguing, this proposition has not been tested directly. It is also possible that

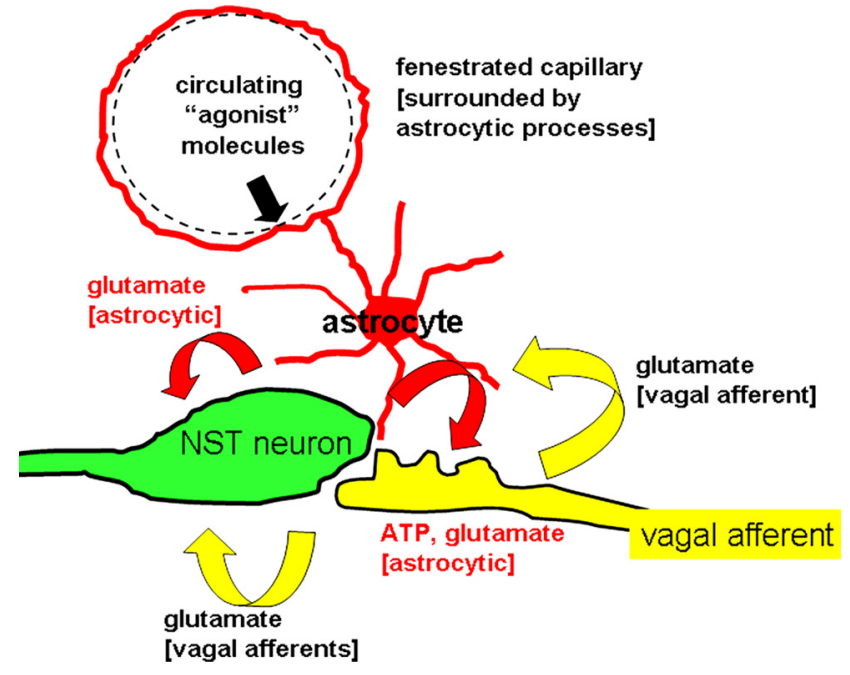

Figure 7. Schematic representation of possible relationship between afferents, astrocytes, and NST neurons. The results from these experiments suggest the hypothesis that local and circulating agents may act directly on glia to powerfully regulate the synaptic strength of hindbrain autonomic reflexes and visceral afferent circuits such as those involved in feeding behavior. Additionally, it is hypothesized that vagal afferent input can modulate the sensitivity of glial chemosensation via glutamatergic input. Such an intertwined system would allow for maximal range of feedback and feedforward regulation of reflexes.

astrocytic release of glutamate may have significant effects at presynaptic terminals via activation of NMDA and metabotropic receptors (Page et al., 2005; Czaja et al., 2006).

Just as astrocytes can release gliotransmitters that alter neural circuit function, a plethora of neuronal afferent transmitters, including norepinephrine, glutamate, GABA, acetylcholine, histamine, adenosine, and ATP (Haydon and Carmignoto, 2006), can potently regulate calcium signaling in astrocytes. Astrocytes may also serve as metabolic sentinels (Marty et al., 2005; Haydon and Carmignoto, 2006). Astrocytes could, in turn, induce changes in autonomic regulation through release of glutamate or other gliotransmitters onto NST neurons that are central to homeostatic control. It is interesting to consider the possibility that visceral afferent inputs could influence the chemosensitivity of NST astrocytes. For example, if glia serve as important chemosensory or sentinel elements for cytokines, chemokines, hormones, nutrients, etc, then neural input to NST glial cells should certainly affect their sensitivity to these physiological parameters. One can envision an extraordinary opportunity for feedback and feedforward regulation of autonomic control reflexes through the sort of general mechanisms outlined in Figure 7. This relationship between glia and presynaptic and postsynaptic neural elements has been termed the "tripartite synapse" (Araque et al., 1999).

In summary, the present studies suggest that PAR1 agonists act directly on astrocytes in the NST. Activated astrocytes, in turn, excite neurons in the NST through the release of glutamate. Excitation of NST neurons that are part of gastric vagovagal reflex control circuitry is known to be involved in normal reflex inhibition of gastric motility and the effect may be responsible for the significant reduction in gastric transit provoked by fourth ventricular thrombin or the PAR1 tethered ligand, SFLLRN-NH2. Such a mechanism may explain why bleeding, trauma (especially bleeding closed head injury), and burns cause profound gastrointestinal stasis characterized by slow transit. 


\section{References}

Akindipe OA, Faul JL, Vierra MA, Triadafilopoulos G, Theodore J (2000) The surgical management of severe gastroparesis in heart/lung transplant recipients. Chest 117:907-910.

Araque A, Parpura V, Sanzgiri RP, Haydon PG (1999) Tripartite synapses: glia, the unacknowledged partner. Trends Neurosci 22:208-215.

Berkowitz N, Schulman LL, McGregor C, Markowitz D (1995) Gastroparesis after lung transplantation. Potential role in postoperative respiratory complications. Chest 108:1602-1607.

Coil JD, Rogers RC, Garcia J, Novin D (1978) Conditioned taste aversions: vagal and circulatory mediation of the toxic unconditioned stimulus. Behav Biol 24:509-519.

Czaja K, Ritter RC, Burns GA (2006) N-methyl-D-aspartate receptor subunit phenotypes of vagal afferent neurons in nodose ganglia of the rat. J Comp Neurol 496:877-885.

Debus E, Weber K, Osborn M (1983) Monoclonal antibodies specific for glial fibrillary acidic (GFA) protein and for each of the neurofilament triplet polypeptides. Differentiation 25:193-203.

Fellin T, Sul JY, D’Ascenzo M, Takano H, Pascual O, Haydon PG (2006) Bidirectional astrocyte-neuron communication: the many roles of glutamate and ATP. Novartis Found Symp 276:208-217; discussion 217-221, 233-237, 275-281.

Flanagan LM, Dohanics J, Verbalis JG, Stricker EM (1992) Gastric motility and food intake in rats after lesions of hypothalamic paraventricular nucleus. Am J Physiol 263:R39-R44.

Garrick T, Mulvihill S, Buack S, Maeda-Hagiwara M, Tache Y (1988) Intracerebroventricular pressure inhibits gastric antral and duodenal contractility but not acid secretion in conscious rabbits. Gastroenterology 95:26-31.

Ghoos Y, Geypens B, Rutgeerts P (2002) Stable isotopes and 13 CO2 breath tests for investigating gastrointestinal functions. Food Nutr Bull 23:166-168.

Ghoos YF, Maes BD, Geypens BJ, Mys G, Hiele MI, Rutgeerts PJ, Vantrappen G (1993) Measurement of gastric emptying rate of solids by means of a carbon-labeled octanoic acid breath test. Gastroenterology 104:1640-1647.

Grill HJ, Schwartz MW, Kaplan JM, Foxhall JS, Breininger J, Baskin DG (2002) Evidence that the caudal brainstem is a target for the inhibitory effect of leptin on food intake. Endocrinology 143:239-246.

Haydon PG, Carmignoto G (2006) Astrocyte control of synaptic transmission and neurovascular coupling. Physiol Rev 86:1009-1031.

Helmchen F (2000) Calibration of fluorescent calcium indicators. In: Imaging neurons: a laboratory manual (Yuste R, Lanni F, Konnerth A, eds), Chap 32, pp 32.1-32.9. Cold Spring Harbor, NY: Cold Spring Harbor Laboratory.

Hermann GE, Rogers RC (2009) TNF activates astrocytes and catecholaminergic neurons in the solitary nucleus: implications for autonomic control. Brain Res 1273:72-82.

Hermann GE, Rogers RC, Bresnahan JC, Beattie MS (2001) Tumor necrosis factor-alpha induces $\mathrm{CFOS}$ and strongly potentiates glutamate-mediated cell death in the rat spinal cord. Neurobiol Dis 8:590-599.

Hermann GE, Van Meter MJ, Rogers RC (2008) CXCR4 receptors in the dorsal medulla: implications for autonomic dysfunction. Eur J Neurosci 27:855-864.

Hua Y, Keep RF, Hoff JT, Xi G (2007) Brain injury after intracerebral hemorrhage: the role of thrombin and iron. Stroke 38:759-762.

Hwang JI, Shin KJ, Oh YS, Choi JW, Lee ZW, Kim D, Ha KS, Shin HS, Ryu SH, Suh PG (2005) Phospholipase C-beta3 mediates the thrombin-induced $\mathrm{Ca} 2+$ response in glial cells. Mol Cells 19:375-381.

Jin YH, Bailey TW, Li BY, Schild JH, Andresen MC (2004) Purinergic and vanilloid receptor activation releases glutamate from separate cranial afferent terminals in nucleus tractus solitarius. J Neurosci 24:4709-4717.

Kang J, Nedergaard M (2000) Calcium imaging of identified astrocytes in hippocampal slices. In: Imaging neurons: a laboratory manual (Yuste R, Lanni F, Konnerth A, eds), Chap 42, pp 42.1-42.11. Cold Spring Harbor, NY: Cold Spring Harbor Laboratory.

Kelly KM (2008) Thrombin: is it on a par with seizures and epilepsy? Epilepsy Curr 8:110-112.

Larson GM, Koch S, O’Dorisio TM, Osadchey B, McGraw P, Richardson JD (1984) Gastric response to severe head injury. Am J Surg 147:97-105.

Lavrentieva A, Kontakiotis T, Bitzani M, Papaioannou-Gaki G, Parlapani A,
Thomareis O, Tsotsolis N, Giala MA (2008) Early coagulation disorders after severe burn injury: impact on mortality. Intensive Care Med 34:700-706.

Lawrence AJ (1995) Neurotransmitter mechanisms of rat vagal afferent neurons. Clin Exp Pharmacol Physiol 22:869-873.

Lee CH, Ruben PC (2008) Interaction between voltage-gated sodium channels and the neurotoxin, tetrodotoxin. Channels (Austin) 2:407-412.

Lee KR, Drury I, Vitarbo E, HoffJT (1997) Seizures induced by intracerebral injection of thrombin: a model of intracerebral hemorrhage. J Neurosurg 87:73-78.

Lu WY, Rhoney DH, Boling WB, Johnson JD, Smith TC (1997) A review of stress ulcer prophylaxis in the neurosurgical intensive care unit. Neurosurgery 41:416-425; discussion 425-416.

Macfarlane SR, Seatter MJ, Kanke T, Hunter GD, Plevin R (2001) Proteinase-activated receptors. Pharmacol Rev 53:245-282.

Marty N, Dallaporta M, Foretz M, Emery M, Tarussio D, Bady I, Binnert C, Beermann F, Thorens B (2005) Regulation of glucagon secretion by glucose transporter type 2 (glut2) and astrocyte-dependent glucose sensors. J Clin Invest 115:3545-3553.

Newman EA (2003) New roles for astrocytes: regulation of synaptic transmission. Trends Neurosci 26:536-542.

Nimmerjahn A, Kirchhoff F, Kerr JN, Helmchen F (2004) Sulforhodamine 101 as a specific marker of astroglia in the neocortex in vivo. Nat Methods 1:31-37.

Page AJ, Young RL, Martin CM, Umaerus M, O'Donnell TA, Cooper NJ, Coldwell JR, Hulander M, Mattsson JP, Lehmann A, Blackshaw LA (2005) Metabotropic glutamate receptors inhibit mechanosensitivity in vagal sensory neurons. Gastroenterology 128:402-410.

Parpura V, Haydon PG (2000) Physiological astrocytic calcium levels stimulate glutamate release to modulate adjacent neurons. Proc Natl Acad Sci U S A 97:8629-8634.

Paton JF, Rogers WT, Schwaber JS (1991) Tonically rhythmic neurons within a cardiorespiratory region of the nucleus tractus solitarii of the rat. J Neurophysiol 66:824-838.

Rogers RC, Hermann GE, Travagli RA (2005) Brainstem control of gastric function. In: Physiology of the gastrointestinal tract, Ed 4 (Johnson LR, ed), pp 851-875. San Diego: Elsevier Academic.

Rogers RC, Van Meter MJ, Hermann GE (2006a) Tumor necrosis factor potentiates central vagal afferent signaling by modulating ryanodine channels. J Neurosci 26:12642-12646.

Rogers RC, Nasse JS, Hermann GE (2006b) Live-cell imaging methods for the study of vagal afferents within the nucleus of the solitary tract. J Neurosci Methods 150:47-58.

Schoonjans R, Van Vlem B, Van Heddeghem N, Vandamme W, Vanholder R, Lameire N, Lefebvre R, De Vos M (2002) The 13C-octanoic acid breath test: validation of a new noninvasive method of measuring gastric emptying in rats. Neurogastroenterol Motil 14:287-293.

Shigetomi E, Kato F (2004) Action potential-independent release of glutamate by $\mathrm{Ca}^{2+}$ entry through presynaptic $\mathrm{P} 2 \mathrm{X}$ receptors elicits postsynaptic firing in the brainstem autonomic network. J Neurosci 24:3125-3135.

Sodhi SS, Guo JP, Maurer AH, O’Brien G, Srinivasan R, Parkman HP (2002) Gastroparesis after combined heart and lung transplantation. J Clin Gastroenterol 34:34-39.

Tomimatsu Y, Idemoto S, Moriguchi S, Watanabe S, Nakanishi H (2002) Proteases involved in long-term potentiation. Life Sci 72:355-361.

Virgili M, Contestabile A, Barnabei O (1995) Simultaneous blockade of non-NMDA ionotropic receptors and NMDA receptor-associated ionophore partially protects hippocampal slices from protein synthesis impairment due to simulated ischemia. Hippocampus 5:91-97.

Volterra A, Meldolesi J (2005) Astrocytes, from brain glue to communication elements: the revolution continues. Nat Rev Neurosci 6:626-640.

Weinstein JR, Gold SJ, Cunningham DD, Gall CM (1995) Cellular localization of thrombin receptor mRNA in rat brain: expression by mesencephalic dopaminergic neurons and codistribution with prothrombin mRNA. J Neurosci 15:2906-2919.

Wolf HK, Buslei R, Schmidt-Kastner R, Schmidt-Kastner PK, Pietsch T, Wiestler OD, Blümcke I (1996) NeuN: a useful neuronal marker for diagnostic histopathology. J Histochem Cytochem 44:1167-1171.

Young B, Ott L, Yingling B, McClain C (1992) Nutrition and brain injury. J Neurotrauma 9 [Suppl 1]:S375-S383. 